\title{
INOVAÇÕES PEDAGÓGICAS E TECNOLÓGICAS: ARTICULAÇÕES CONSTRUÍDAS NOS CURSOS DE PEDAGOGIA
}

\author{
Andréia Morés ${ }^{1}$
}

\section{INTRODUZINDO A CAMINHADA ACADÊMICA ${ }^{2}$}

No presente artigo busca-se sistematizar as reflexões construídas a partir da investigação realizada no Curso de Pedagogia presencial e EaD da Universidade de Caxias do Sul (UCS). A formação acadêmica presente no curso de Pedagogia contempla o aporte de estudos teóricos e práticos construídos junto às diversas disciplinas presentes no currículo do Curso, dentre as quais estão os estágios curriculares obrigatórios realizados ao longo do curso.

Assim, o curso de Pedagogia da UCS, apoiado em suas Diretrizes Curriculares Nacionais (DCN), (2006), propõe avanços em suas práticas de estágio, envolvendo os espaços escolares e não escolares ${ }^{3}$. Nesse sentido, demanda-se uma visão mais dinâmica de educação e de pedagogia, que contribua para a formação de novos saberes inerentes ao ofício pedagógico e permita maior autonomia aos processos de ensino e aprendizagem.

Imersos no atual contexto de formação, destaca-se a importância deste estudo, pois potencializa a Inovação e suas relações com os processos de formação acadêmica, o aprimoramento das relações teóricas e práticas da pesquisa e das inovações pedagógicas e tecnológicas vivenciadas durante os estágios curriculares obrigatórios. Para o desenvolvimento da presente investigação utiliza-se a metodologia qualitativa, com ênfase no método estudo de caso, seguindo os estudos de Yin (2005). No estudo de caso, conforme a expressão sugere, examina-se o "caso". Esse método possibilita a investigação do contexto na vida real em que ele acontece, podendo-se ilustrar certos tópicos, abarcando de modo descritivo e qualitativo o cotidiano em estudo, o

\footnotetext{
${ }^{1}$ Doutora em Educação(UFRGS). Professora na Universidade de Caxias do Sul, Caxias do Sul, RS,Brasil.E-mail: anmores@ucs.br

${ }_{2}^{2}$ O presente texto foi submetido para avaliação na XI ANPED Sul 2016.

3 A terminologia não escolar está sendo usada de acordo com as DCN para o Curso de Graduação em Pedagogia, licenciatura (2006).
} 
que permite que se investiguem as inovações pedagógicas e tecnológicas presentes na formação acadêmica.

\section{INOVAÇÕES PEDAGÓGICAS E TECNOLÓGICAS NA FORMAÇÃO ACADÊMICA}

A formação acadêmica, historicamente, tem se caracterizado pelo mito da racionalidade científica, inspirada em um modelo universitário autárquico, com supervisão das ciências exatas e tecnológicas e, consequentemente, a desvalorização das ciências humanas. Assim, os cursos superiores instalados no Brasil voltaram-se diretamente para a formação de profissionais que exerciam determinada profissão. Os currículos eram seriados, com programas fechados, e incluíam somente disciplinas de interesse imediato ao exercício daquela profissão, procurando formar profissionais especialistas em determinada área.

Havendo, portanto, a necessidade de avançar nos processos de formação acadêmica, é preciso desenvolver um trabalho que vá além do academicismo institucional, em uma proposta crítica, reflexiva, investigativa, criativa e construtiva. Isso possibilitará o rompimento das barreiras acadêmicas vividas nos espaços institucionais, fazendo com que haja articulação entre a universidade e os espaços de atuação pedagógica, escolares e não escolares e se possa propor um ação interdisciplinar de construção do conhecimento, sem perder de vista seus objetivos e muito menos deixar de exercer sua função social e educacional.

Historicamente, o profissional egresso do curso de Pedagogia estava habilitado para a docência, especialmente na Educação Infantil, nos Anos Iniciais e em matérias pedagógicas do Ensino Médio. Atualmente, de acordo com as DCN (2006), houve mudança, propiciando ampliar a abrangência do Curso de Pedagogia quanto à sua formação. $\mathrm{O}$ art. $2^{\circ}$ das DCN define que o Curso de Pedagogia destina-se à formação inicial para o exercício da docência na Educação Infantil e nos anos iniciais do Ensino Fundamental, nos cursos de Ensino Médio, na modalidade Normal, e em cursos de Educação Profissional na área de serviços e apoio escolar, e em outras áreas nas quais sejam previstos conhecimentos pedagógicos. 
Assim, o processo de formação e atuação pedagógica requer a compreensão de saberes e conhecimentos científicos, pedagógicos e educacionais, acrescidos de sensibilidade, investigação e criatividade para encarar as situações ambíguas, incertas, conflituosas e, por vezes, complexas, presentes nos contextos educativos, sendo necessário que o pedagogo construa novos saberes inerentes ao seu ofício profissional.

Nóvoa (1992, p. 26), em seus escritos sobre a docência, ressalta que "a troca de experiências e a partilha de saberes consolidam espaços de formação mútua, nos quais cada professor é chamado a desempenhar, simultaneamente, o papel de formador e de formado". Assim, pode-se dizer que é (re)significada, desse modo, a compreensão de que a docência se constitui de múltiplos saberes e que estes devem ser os inspiradores da formação. Portanto, deve-se fazer da universidade e das instituições educacionais e sociais um espaço formador que desperte o interesse dos alunos, tornando o trabalho pedagógico um espaço de construção, de inovação de conhecimentos, em que as práticas educativas estejam pautadas e contextualizadas a partir das necessidades e das realidades vividas pelo educando.

Assim, o contexto de formação acadêmica no Ensino Superior sentese desafiado frente às demandas de ordem pedagógica, política e social. Para tal, é fundamental investir em concepções e ações que contemplem o estudo da inovação, da inovação pedagógica e tecnológica nos processos de formação e atuação pedagógica.

O estudo da inovação compreende o desafio de romper com a concepção epistêmica da ciência enquanto princípio arraigado nas concepções do paradigma da modernidade. E dentre os novos movimentos epistêmicos que compreendem um conjunto de perspectivas, segundo Santos (2006), são consideradas as epistemologias plurais da prática científica, da diversidade e da pluralidade que caracterizam a transição paradigmática.

É com esse olhar de inovação que se adentra nos estudos da inovação pedagógica, a partir dos referenciais de Leite, Cunha e Lucarelli (1999), que dão visibilidade às inovações produzidas no interior do microespaço ao macro educacional: mudanças nas relações dentro da sala de aula, onde os sujeitos são protagonistas de suas circunstâncias e 
aprendizagens; mudanças na configuração da docência, possibilitando que diferentes atores (alunos, professores, pesquisadores, a comunidade) sejam partícipes de um processo de aprendizagem; a inclusão das tecnologias no auxilio didático dos processos que envolvem o ensinar e o aprender na universidade; rompimentos de visões hegemônicas na universidade.

Adentra-se, assim, na inovação tecnológica, com base nos estudos de Sancho (2006), em que o autor assegura que as tecnologias são consideradas uma ferramenta que mudará a sociedade, envolvendo diretamente $o$ aspecto educacional e social:

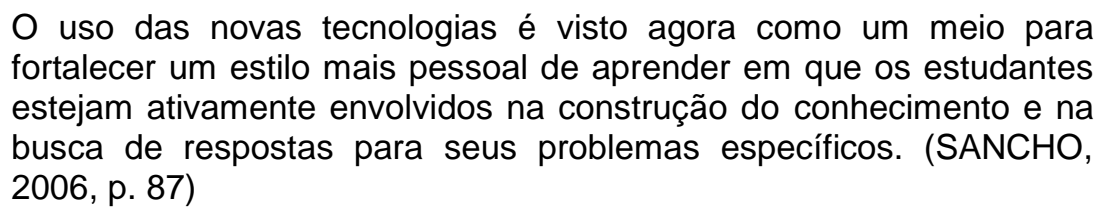

Dessa forma, o uso das tecnologias possibilita e desafia a construção de novas habilidades, possibilitando que o aluno desenvolva maior autonomia na construção de sua aprendizagem. Também fortalece as interações, trocas e a construção coletiva entre grupos, evitando distanciamento entre fronteiras, ou seja, há a possibilidade de se romper com os distanciamentos de territórios em prol de uma construção coletiva e democrática.

A formação acadêmica deve promover condições para que o acadêmico construa conhecimento sobre as tecnologias, e entenda por que e como integrar as tecnologias em sua prática pedagógica. Para tal, compreende-se a importância de um currículo de curso que contemple uma visão articulada com as inovações pedagógicas e tecnológicas apoiadas na concepção contra-hegemônica e democrática; que vise ao fortalecimento de estudos e pesquisas que tensionem e enriqueçam as práticas desenvolvidas em sala de aula, a fim de promover e indagar práticas inovadoras em prol de um processo de aprendizagem significativo.

Com essa visão de currículo é que nos movimentamos em direção aos estágios curriculares obrigatórios do curso de Pedagogia. Segundo Pimenta e Lima (2004, p. 24), o estágio curricular tem a finalidade de "integrar o processo de formação do aluno, futuro profissional, de modo a considerar o 
campo de atuação como objeto de análise, de investigação e de interpretação crítica, a partir dos nexos com as disciplinas dos cursos".

De acordo com a visão de Pimenta e Lima (2004), o estágio curricular é um campo de formação, de produção de conhecimentos, de práticas, de saberes e vivências, sendo este um campo significativo para estudo e investigação na formação acadêmica. É com esse viés que se adentra neste estudo, investindo em uma formação que propicie condições para que o acadêmico consiga contextualizar o aprendizado e a experiência desenvolvida durante sua formação acadêmica com a realidade educacional presente no cotidiano de atuação pedagógica.

A partir do exposto, considera-se a formação acadêmica, em especial os estágios obrigatórios, um momento de articulação teórica e prática, de investigação e problematização sobre o pensar e o fazer pedagógico, mobilizando a construção de saberes inerentes ao exercício profissional, sendo, assim, um campo propulsor para o desenvolvimento de saberes e práticas que contemplem a inovação pedagógica e tecnológica.

\section{PERCURSO METODOLÓGICO: CONSTRUÇÃO E ANÁLISE DOS DADOS}

Os caminhos percorridos nesta pesquisa permitem a inserção da metodologia qualitativa em educação, proporcionando uma aproximação entre o pesquisador, o campo de investigação e os sujeitos da pesquisa. Esse tipo de metodologia proporciona a compreensão detalhada da observação e dos procedimentos metodológicos que envolvem a investigação. Assim, para o desenvolvimento qualitativo desta investigação foram utilizados os estudos de Bogdan e Biklen, os quais afirmam que "o processo de condução da investigação qualitativa reflete uma espécie de diálogo entre os investigadores e os respectivos sujeitos, dado estes não serem abordados por aqueles de uma forma neutra". (1994, p. 51).

Seguindo as referências da metodologia qualitativa enfatiza-se o Estudo de Caso que propicia conhecer e examinar em profundidade o caso, em seu contexto natural, reconhecendo-se sua complexidade. Segundo Yin (2005, p. 13), "o estudo de caso é uma investigação empírica que investiga um fenômeno no seu ambiente natural, quando as fronteiras entre o fenômeno e o 
contexto não são bem definidas (...) em que múltiplas fontes de evidência são usadas".

Assim, a presente pesquisa está sendo desenvolvida junto ao Curso de Pedagogia Presencial e EaD, da Universidade de Caxias do Sul. Os sujeitos da pesquisa são estagiários de ambos os cursos, matriculados em disciplinas de estágios, convidados a participar de modo voluntário. A metodologia de estudos de caso inclui análise documental do Projeto do Curso de Pedagogia presencial e EaD, questionários, textos produzidos nas disciplinas de Estágio e leituras de referências bibliográficas que nortearão toda a pesquisa.

A presente investigação encontra-se em fase parcial de construção e análise de dados. Para melhor compreensão do estudo de caso, iniciamos apresentando a instituição e seu projeto de curso e, posteriormente, adentramos aos depoimentos dos estudantes.

A UCS é uma instituição comunitária e abrange uma área de aproximadamente 70 municípios, que estão compreendidos em seu programa de regionalização, e situam-se nas regiões da Encosta Superior do Nordeste, dos Campos de Cima da Serra e do Vale do Caí, no Rio Grande do Sul. O curso de Pedagogia presencial da UCS iniciou em 1960, na antiga Faculdade de Filosofia, Ciências e Letras, que se integrou à UCS no ano de 1967, completando, assim, 56 anos de experiência na formação pedagógica e docente. Investindo qualitativamente na formação de professores, em 2004 a UCS criou o primeiro Curso de Pedagogia EaD, sendo pioneira no Estado.

A organização curricular presente nos Projetos Pedagógicos de ambos o curso tem, por princípio, o conhecimento da escola como organização complexa cuja função é a de promover a educação para e na cidadania; a pesquisa, a análise e a aplicação do resultado de investigações de interesse da área educacional; a participação na gestão de processos educativos, na organização e no funcionamento de sistemas e instituições de ensino; a ampliação e a inclusão das TIC em espaços de formação e atuação profissional, construindo, assim, novas redes de interação e aprendizagem (UCS, 2014).

Para o desenvolvimento desses princípios o Projeto Pedagógico do Curso (2014) referenda a metodologia embasada nas dimensões construtivistas, interacionistas, sociais, culturais e transcendentes. Essa 
escolha implica uma postura que propicia o diálogo, desencadeado a partir do respeito às finalidades do curso, aos interesses e necessidades dos estudantes, estimulando a autonomia de pensamento e a construção de aprendizagens significativas, visando não apenas ao aprender a fazer, mas, sobretudo, ao aprender a aprender, ao aprender a ser, e ao aprender a conviver, articulado com os quatro pilares da educação sistematizados por Delors (2006).

O aporte teórico que norteia esta análise está apoiado nos estudos de Leite, Cunha e Lucarelli (1999), Lima e Pimenta (2004; 2014) e Sancho (2006), dentre outros, que em seus estudos e teorias referendam a construção da importância de uma formação apoiada em concepções científicas que propõem a ruptura das visões teóricas e práticas vivenciadas na ciência moderna.

É com este olhar que se adentra nos estudos da inovação pedagógica, a partir dos referenciais de Leite, Cunha e Lucarelli (1999), que dão visibilidade às inovações produzidas nos contextos e espaços educacionais. Para tal, considera-se importante que a formação acadêmica, em especial os estágios do Curso de Pedagogia, propicie momentos de estudos, de pesquisa e de construção de novos conhecimentos.

Conforme os depoimentos a seguir, as inovações na formação acadêmica proporcionam: "Sair do senso comum, buscar novos conhecimentos, conhecer novos espaços." (Estagiária LW); "Novas experiências, conhecimentos teórico e práticos interligados e fundamentados. (Acadêmica LW).

Nos depoimentos das acadêmicas observa-se que há a visibilidade da importância da inovação, pois é potencializadora da mudança, da superação do senso comum e da construção de conhecimentos teóricos e práticos que qualificam o processo de ensino e aprendizagem. Seguindo esse pensamento tem-se o depoimento do estagiário DZ: "Quanto às inovações pedagógicas tive uma experiência excelente, pois foi possível conhecer e vivenciar a pesquisa em sala de aula".

Assim, enfatiza-se a importância de o currículo do curso contemplar a pesquisa como princípio educativo, investigando, com os alunos, a realidade escolar, desenvolvendo neles a atitude investigativa em suas atividades 
profissionais, tornando a pesquisa um princípio formativo. Dessa forma, faz-se a aproximação dos princípios defendidos por Pimenta; Lima (2004, p. 14), "que aponta para o desenvolvimento do estágio como uma atitude investigativa, que envolve a reflexão e a intervenção [...]". De acordo com essas autoras, a construção do conhecimento acontece através da prática da pesquisa, e só ocorre o ensinar e o apreender significativamente quando estes decorrem de uma postura investigativa de trabalho.

No âmbito do processo educativo compreende-se que a educação é uma prática intencionalizada pela teoria. Assim, nessa prática centra-se a importância do estágio para o processo de formação de pedagogo e sua imersão na pesquisa, conforme se constata no seguinte depoimento:

\begin{abstract}
A partir das minhas experiências com a pedagogia em espaços não escolares, proporcionada pelo Estágio, com orientação do professor orientador de estágio, considero a intervenção pedagógica uma mediação pedagógica intencional que envolve processos de ensino e aprendizagem em diferentes situações ou ambientes.

Toda proposta de intervenção pedagógica, surge da análise e pesquisa dos sujeitos que estão envolvidos no processo. Após a análise da realidade educacional, busca-se pesquisar sobre os assuntos que a envolvem e planejar a ação, ou seja, o que deve ser feito. Então, é possível avaliar quais são as melhores intervenções pedagógicas e como elas devem ocorrer para facilitar, auxiliar e implementar o processo pedagógico.

Toda a intervenção pedagógica deve visar a evolução dos sujeitos envolvidos em algum aspecto, portanto, ela deve ser motivadora, adequada à realidade educacional e apropriada para os objetivos propostos serem alcançados. (Estagiária GB)
\end{abstract}

Esse depoimento sinaliza a importância do trabalho pedagógico realizado junto aos estágios, na imersão em um planejamento que prima por uma intervenção pedagógica intencional e articulada com a realidade vivida no campo de estágio.

Compreende-se que a investigação deva fazer parte das disciplinas durante o processo formativo, produzindo articulações diretas com os espaços escolares e não escolares. Isto porque, diz Nóvoa (1992, p. 28), "a formação passa pela experimentação, pela inovação, pelo ensaio de novos modos de trabalho pedagógico. E, por uma reflexão crítica sobre sua utilização, a formação passa por um processo de investigação, diretamente com as práticas educativas". Considera-se, assim, que avançar no processo de 
desenvolvimento profissional no ensino superior, mediante a preparação pedagógica, é, hoje, um desafio a ser enfrentado.

Sendo assim, observa-se que os professores do Curso de Pedagogia têm proporcionado uma formação acadêmica articulada com as inovações tecnológica, conforme se constata no depoimento a seguir: " $E$, quanto às inovações tecnológicas percebeu-se que a grande maioria dos professores proporcionaram vivências com as tecnologias em sala de aula." (Estagiário DZ)

Essas vivências e práticas vão ao encontro das concepções de Sancho (2006, p. 87), o qual assegura que as tecnologias se apresentam como uma ferramenta que mudará a face da sociedade, envolvendo o aspecto educativo e social. E o autor afirma:

\begin{abstract}
O uso das novas tecnologias é visto agora como um meio para fortalecer um estilo mais pessoal de aprender em que os estudantes estejam ativamente envolvidos na construção do conhecimento e na busca de respostas para seus problemas específicos. Ao mesmo tempo, estão usando suas habilidades para aprender como são utilizados os próprios meios tecnológicos (SANCHO, 2006, p. 88).
\end{abstract}

As novas tecnologias, portanto, mobilizam e desafiam novas formas de ensinar e aprender, proporcionando maior autonomia, facilitando as interações virtuais, construções coletivas, evitando, assim, o distanciamento entre fronteiras, contribuindo significativamente com os processos de formação acadêmica e as vivências realizadas junto aos estágios. Em seu relato, a Estagiária CV afirma:

Através das vivências na universidade aprendi a importância do uso da tecnologia no processo de formação e considero que houve benefícios os quais contribuíram em minhas práticas de estágio, principalmente em relação à comunicação, à pesquisa e o fácil acesso ao conhecimento devido às tecnologias.

As tecnologias, portanto, implicam mudança de hábitos no ato de aprender, em que o computador passa a fazer parte da vida diária, e os alunos passam a ler e-books, artigos, utilizando as bibliotecas digitais, gerando a mudança nos hábitos culturais. Assim, Sancho (2006) destaca a importância de educar os alunos para a Sociedade do Conhecimento, para que possam 
pensar e intervir de forma crítica e autônoma, a fim de solucionar problemas e buscar novas soluções através do uso das tecnologias.

Em seus estudos, Lima e Pimenta (2004 p.24) afirmam que o estágio curricular tem como finalidade "integrar o processo de formação do aluno, futuro profissional, de modo a considerar o campo de atuação como objeto de análise, de investigação e de interpretação crítica, a partir dos nexos com as disciplinas dos cursos." No entanto, corroborando com a visão de Lima e Pimenta (2004), compreende-se o estágio curricular como um campo de formação, de produção de conhecimentos, de práticas, de saberes e vivências, sendo este um campo significativo para estudo e investigação na formação acadêmica.

Dessa forma, seguindo o pensamento de Pimenta e Lima compreende-se que o estágio é a "atividade teórica de conhecimento, fundamentação, diálogo e intervenção na realidade (...)" (2012, p. 43). Assim, sendo a pedagogia o campo teórico e investigativo da educação reitera-se a importância de um currículo que propicie, ao longo da formação acadêmica, estudos e práticas relacionadas aos contextos escolares e não escolares, imbricadas nos aspectos educacionais e sociais. O depoimento a seguir reitera esse pensamento:

\footnotetext{
Muitos quando falam em pedagogia logo remetem a docência, e nos dias de hoje sabemos que o campo de atuação do pedagogo tem se estendido para além da sala de aula, o que a meu ver é muito positivos, pois vivemos em sociedade e a educação o ensino deve estar presente nestes campos também. Portanto se faz necessário mais estudos sobre esse leque de oportunidades. (Estagiária FD)

$\mathrm{E}$, durante o estágio tivemos a oportunidade de estar vivenciando e conhecendo como fun=cionam estas outras áreas, resultando em novos aprendizados, novas visões e acima de tudo contribuindo de forma significativa para a formação pessoal e profissional de um pedagogo. (Estagiária FD)
}

A estagiária FD fala sobre os avanços obtidos durante o estágio, estando de acordo com as Diretrizes Curriculares Nacionais que indicam novos espaços de atuação pedagógica, como se lê no artigo 4을

Art. 4ํ - O curso de Licenciatura em Pedagogia destina-se à formação de professores exercer funções de magistério na Educação Infantil e nos anos iniciais do Ensino Fundamental, nos cursos de Ensino 
Médio, na modalidade Normal, de Educação Profissional na área de serviços e apoio escolar e em outras áreas nas quais sejam previstos conhecimentos pedagógicos.

Parágrafo único. As atividades docentes também compreendem participação na organização e gestão de sistemas e instituições de ensino, englobando:

I - planejamento, execução, coordenação, acompanhamento e avaliação de tarefas próprias do setor da Educação;

II - planejamento, execução, coordenação, acompanhamento e avaliação de projetos e experiências educativas não escolares;

III - produção e difusão do conhecimento científico-tecnológico do campo educacional, em contextos escolares e não escolares (BRASIL, 2014, p.1).

De acordo com o exposto nas Diretrizes Curriculares Nacionais, Pimenta e Libâneo (2006, p. 29) afirmam que "a ação pedagógica não se resume a ações docentes, de modo que, se todo trabalho docente é trabalho pedagógico, nem todo trabalho pedagógico é trabalho docente". Essa concepção possibilita adentrar no desenvolvimento de novas práticas pedagógicas e educativas, desafiando os alunos a conhecerem os espaços escolares e também os espaços não escolares, o que é destacado pela estagiária CT:

Durante o estágio de Pedagogia pudemos conhecer diversos exemplos de intervenções pedagógicas realizadas pelas alunas da disciplina, sendo esses espaços: hospitais, comunidades, ONG's, coordenação e gestão escolar, entre outros e além disso, conhecemos a postura que cada pedagogo obteve nesses diferentes espaços. O pedagogo que realiza essa intervenção pedagógica tem uma postura totalmente diferente da postura docente, pois ele precisa se adaptar à realidade do local em que está inserido, conhecer essa realidade e a partir disso realizar a sua intervenção. (Estagiária CT)

A fala acima afirma a importância de o pedagogo conhecer seus espaços de atuação a fim de poder realizar uma intervenção pedagógica. Segundo Libâneo (2006, p. 68), "o pedagogo é o profissional que atua em várias instâncias da prática educativa, direta ou indiretamente, ligadas à organização e aos processos de transmissão e assimilação de saberes e modos de ação". Para tanto, requer-se do pedagogo o preparo para atuar nos diversos campos educativos, estando de acordo com o perfil do egresso do Curso contemplado no Projeto Pedagógico.

Assim,, observa-se no rol dos depoimentos prestigiados na pesquisa que estão presentes vivências, práticas e estudos pedagógicos condizentes 
com as necessidades vivenciadas durante os estágios, em que potencializam o aprimoramento da inserção pedagógica em espaços escolares e não escolares durante a formação acadêmica realizada durante o curso de Pedagogia.

No entanto, destaca-se a universidade, mais especificamente o curso de Pedagogia, está desenvolvendo um trabalho de que oportuniza a articulação entre as concepções teóricas, as vivências práticas, a imersão na pesquisa e o desenvolvimento das inovações pedagógicas e tecnológicas, contribuído qualitativamente para com os processos de formação acadêmica.

\section{CAMINHOS CONCLUSIVOS}

Adentrando na caminhada conclusiva desta investigação, aponta-se a importância do Curso de Pedagogia da UCS investir em uma formação que potencialize a inovação de modo a dar condições para que os estagiários consigam construir novos conhecimentos e experiências durante sua formação, estabelecendo relações com a realidade educacional presente no cotidiano de atuação pedagógica.

No entanto, no presente estudo percebe-se que a formação acadêmica, especialmente os estágios obrigatórios, estão aliados às inovações pedagógicas e tecnológicas e priorizam momentos de articulação teórica e prática, de pesquisa em sala de aula, de vivências com as tecnologias, potencializando a construção de novos conhecimentos e experiências pedagógicas.

Esses momentos fortalecem a visão para a construção de novas práticas pedagógicas que primem pelo fortalecimento da atuação pedagógica escolar e não escolar, nas quais sejam previstos conhecimentos pedagógicos, de acordo com as legislações vigentes, e permitam ao Pedagogo conhecer e atuar em novos campos.

Portanto, a presente investigação destaca que as inovações pedagógicas e tecnológicas e suas articulações com as práticas realizadas nos estágios obrigatórios dão visibilidade à trajetória da formação de pedagogos na Universidade e o fortalecimento das práticas construídas nos espaços educacionais. 


\section{REFERÊNCIAS}

BRASIL. Resolução CNE/CP № 1, de 15/05/2006. Institui Diretrizes Curriculares Nacionais para o Curso de Graduação em Pedagogia, licenciatura. Disponível em:< http://portal.mec.gov.br/cne/arquivos/pdf/rcp01_06.pdf>. Acesso: 12 mar. 2014.

BOGDAN, Robert; BIKLEN, Sari. Investigação qualitativa em educação: uma introdução à teoria e aos métodos. Trad. de Porto Editora. Portugal: Porto, 1994.

DELORS, Jacques. Educação: um tesouro a descobrir. 10.ed. São Paulo: Cortez, 2006.

FREIRE, Paulo. Pedagogia da Autonomia: saberes necessários à prática educativa. São Paulo: Paz e Terra,1998.

LEITE, Denise; CUNHA, Maria Isabel da Cunha; LUCARELLI, Elisa, et al.. Inovação na Universidade: a pesquisa em parceria (1999). Disponível em:<www.interface.org.br/revista4/ensaio3.pdf. Acesso em 10/10/2009.

LIBÂNEO, José Carlos. Ainda as perguntas: o que é pedagogia, quem é o pedagogo, o que deve ser o curso de Pedagogia. In: PIMENTA, Selma Garrido. Pedagogia e pedagogos: caminhos e perspectivas. São Paulo: Cortez, 2006.

NÓVOA, Antonio. Os professores e as histórias da sua vida. In: NÓVOA, Antonio. (Org.). Vidas de professores. Porto: Porto Editora, 1992.

PIMENTA, Selma G. Formação de Professores: saberes e identidade da docência. In: _Saberes pedagógicos e atividade docente. São Paulo, Cortez, 1999.

PIMENTA, Selma G.; LIMA, Maria S. L. Estágio e docência. 2. ed. São Paulo: Cortez, 2004.

PIMENTA, Selma Garrido (Org.). Pedagogia e pedagogos: caminhos e perspectivas. São Paulo: Cortez, 2006. 
PIMENTA, Selma Garrido; LIMA, Maria Socorro Lucena. Estágio e Docência Teoria e Prática: Diferentes Concepções. (p. 133 a 152). In: BRABO, Tânia Suely Antonelli Marcelino; CORDEIRO, Ana Paula; Milanez, Simone Ghedini Costa (org.). Formação da pedagoga e do pedagogo: pressupostos e perspectivas. São Paulo: Cultura Acadêmica, 2012. Disponível em:<https://www.marilia.unesp.br/Home/Publicacoes/formacao-dopedagogo_e-book.pdf>. Acesso: 10 mar. 2014.

SANCHO, Juana Maria; HERNÁNDEZ, Fernando. Tecnologias para transformar a educação. Porto Alegre: Artmed, 2006.

SANTOS, Boaventura de Souza. A gramática do tempo: para uma nova cultura política. São Paulo: Cortez. 2006.

UNIVERSIDADE DE CAXIAS DO SUL - UCS. Projeto Pedagógico - Curso de Licenciatura em Pedagogia. Caxias do Sul, 2014.

YIN, Robert K. Estudo de caso: planejamento e método. 3. ed. Porto Alegre: Bookma, 2005. 